\title{
Use of open mobile mapping tool to assess human mobility traceability in rural offline populations with contrasting malaria dynamics
}

Gabriel Carrasco-Escobar ${ }^{\text {Corresp., }}{ }^{1,2}{ }^{2}$, Marcia C. Castro ${ }^{3}$ ， Jose Luis Barboza ${ }^{1}$, Jorge Ruiz-Cabrejos ${ }^{1}$, Alejandro Llanos-Cuentas ${ }^{4}$, Joseph M Vinetz ${ }^{4,5}$, Dionicia Gamboa ${ }^{1,4,6}$

1 Laboratorio ICEMR-Amazonia, Laboratorios de Investigación y Desarrollo, Facultad de Ciencias y Filosofía, Universidad Peruana Cayetano Heredia, Lima, Peru

2 Division of Infectious Diseases, Department of Medicine, University of California, San Diego, La Jolla, California, United States

3 Department of Global Health and Population, T.H. Chan School of Public Health, Harvard University, Boston, Massachusetts, United States

4 Instituto de Medicinal Tropical Alexander von Humboldt, Universidad Peruana Cayetano Heredia, Lima, Peru

5 Department of Infectious diseases, School of Medicine, Yale University, New Haven, Connecticut, United States

6 Departamento de Ciencias Celulares y Moleculares, Facultad de Ciencias y Filosofía, Universidad Peruana Cayetano Heredia, Lima, Peru

Corresponding Author: Gabriel Carrasco-Escobar

Email address: gabriel.carrasco@upch.pe

Infectious disease dynamics are affected by human mobility more powerfully than previously thought, and thus reliable traceability data are essential. In rural riverine settings, lack of infrastructure and dense cloud coverage deter the implementation of cutting-edge technology to collect human mobility data. To overcome this challenge, this study proposed the use of a novel open mobile mapping tool, GeoODK. This study consists of a purposive sampling of 33 participants in 6 villages with contrasting patterns of malaria transmission that demonstrates a feasible approach to map human mobility. The selfreported traceability data allowed the construction of the first human mobility framework in rural riverine villages in the Peruvian Amazon. The mobility spectrum in these areas resulted in travel profiles ranging from 2 hours to 19 days; and distances between 10 to $167 \mathrm{~km}$. Most Importantly, occupational-related mobility profiles with the highest displacements (in terms of time and distance) were observed in commercial, logging, and hunting activities. These data are consistent with malaria transmission studies in the area that show villages in watersheds with higher human movement are concurrently those with greater malaria risk. The approach we describe represents a potential tool to gather critical information that can facilitate malaria control activities. 


\title{
Use of open mobile mapping tool to assess human mobility
}

\author{
traceability in rural offline populations with contrasting
}

malaria dynamics

1 Gabriel Carrasco-Escobar ${ }^{1,2,}$, Marcia C. Castro ${ }^{3}$, Jose Luis Barboza ${ }^{1}$, Jorge Ruiz-

2 Cabrejos ${ }^{1}$, Alejandro Llanos-Cuentas ${ }^{4}$, Joseph M. Vinetz ${ }^{4,5}$, Dionicia Gamboa ${ }^{1,4,6}$

$4 \quad{ }^{1}$ Laboratorio ICEMR-Amazonia, Laboratorios de Investigación y Desarrollo, Facultad de

5 Ciencias y Filosofía, Universidad Peruana Cayetano Heredia, Lima, Peru.

6 2Division of Infectious Diseases, Department of Medicine, University of California San

7 Diego, La Jolla, CA, USA

8 '3epartment of Global Health and Population, T.H. Chan School of Public Health,

9 Harvard University, Boston, MA, USA

$10{ }^{4}$ Instituto de Medicinal Tropical Alexander von Humboldt, Universidad Peruana

11 Cayetano Heredia, Lima, Peru

12 5Department of Infectious diseases, School of Medicine, Yale University, New Haven, 13 CT, USA

14 'Departamento de Ciencias Celulares y Moleculares, Facultad de Ciencias y Filosofía,

15 Universidad Peruana Cayetano Heredia, Lima, Peru

* Correspondence:

19 Gabriel Carrasco Escobar, MSc: gabriel.carrasco@upch.pe 


\section{ABSTRACT (200 words)}

24 Infectious disease dynamics are affected by human mobility more powerfully than

25 previously thought, and thus reliable traceability data are essential. In rural riverine

26 settings, lack of infrastructure and dense cloud coverage deter the implementation of

27 cutting-edge technology to collect human mobility data. To overcome this challenge, this

28 study proposed the use of a novel open mobile mapping tool, GeoODK. This study

29 consists of a purposive sampling of 33 participants in 6 villages with contrasting patterns

30 of malaria transmission that demonstrates a feasible approach to map human mobility.

31 The self-reported traceability data allowed the construction of the first human mobility

32 framework in rural riverine villages in the Peruvian Amazon. The mobility spectrum in

33 these areas resulted in travel profiles ranging from 2 hours to 19 days; and distances

34 between 10 to $167 \mathrm{~km}$. Most Importantly, occupational-related mobility profiles with the

35 highest displacements (in terms of time and distance) were observed in commercial,

36 logging, and hunting activities. These data are consistent with malaria transmission

37 studies in the area that show villages in watersheds with higher human movement are

38 concurrently those with greater malaria risk. The approach we describe represents a

39 potential tool to gather critical information that can facilitate malaria control activities. 


\section{1. INTRODUCTION}

42 The process of globalization has expanded the limits of human mobility and

43 connectivity, creating a new dimension for infectious diseases dynamics and spread

44 (Prothero, 1977; Martens \& Hall, 2000; Stoddard et al., 2009; Funk, Salathé \& Jansen,

45 2010; Tatem \& Smith, 2010). Focused on malaria, human mobility was considered to be

46 a key factor for control and eventually elimination (Pindolia et al., 2012; Wesolowski et

47 al., 2012; Sturrock et al., 2015; Peeters Grietens et al., 2015), encompassing

48 International (Tatem \& Smith, 2010; Findlater \& Bogoch, 2018), seasonal (Buckee,

49 Tatem \& Metcalf, 2017; Wesolowski et al., 2017), and local migration (Searle et al., 50 2017).

51 Recently, new technologies have leapfrogged major challenges to collecting reliable

52 mobility data. One successful project was conducted on mobile phone data to assess

53 human mobility (González, Hidalgo \& Barabási, 2008; Barabási, 2009) and its

54 application to understand malaria dynamics (Buckee et al., 2013; Wesolowski et al.,

55 2016). Similarly, Google Location History (GLH) was explored as another potential

56 source of human mobility data (Ruktanonchai et al., 2018). Finally, data-collecting

57 wearables such as GPS data-loggers have been proposed to collect fine-scale

58 traceability data (Vazquez-Prokopec et al., 2013; Searle et al., 2017).

59 However, lack of telephone landline, mobile phone coverage or internet infrastructure

60 prevents the use of approaches using secondary data (i.e. cellular records and GLH) in

61 rural settings, as in the Amazon region. Moreover, dense tree coverage reduces the

62 performance and reliability of GPS data-logger devices (Rempel, Rodgers \& Abraham, 
63 1995; Sigrist, Coppin \& Hermy, 1999; Danskin et al., 2009). Thus, our study sought to

64 estimate human mobility based on self-reported traceability data collected with a novel

65 open mobile mapping tool, GeoODK. This app provides a suite for offline mapping and

66 visualization of collected geo-referenced data on mobile devices. The main

67 geographical formats in GeoODK are geopoint (point), geoshape (polygon), and

68 geotrace (polyline) that can be associated with other types of information.

69 Although potential benefits of the use of GeoODK for malaria control was previously

70 demonstrated for household mapping (Fornace et al., 2018), our study explored its

71 geometry mapping features for georeferencing human mobility trajectories. At this

72 micro-geographic scale, mobility data would be most informative to address the

73 exposure to infection (Pindolia et al., 2012) relative to heterogeneous environmental

74 and transmission landscapes (Perchoux et al., 2013), in order to better understand the

75 underlying dynamics in villages with contrasting malaria transmission in rural riverine

76 Peruvian Amazon.

78 2. MATERIAL AND METHODS

79 2.1. Ethics

80 The study was approved by the Ethics Review Board of the Regional Health Directorate

81 of Loreto, Universidad Peruana Cayetano Heredia in Lima and the Human Subjects

82 Protection Program of the University of California, San Diego, USA. IR approval number

83 \#101518. Participants were enrolled upon written consent. 


\section{2.2. Case Study}

85 We evaluated the use of GeoODK, an open-source mobile mapping tool, to assess

86 human mobility patterns in rural villages in Loreto Region in the Peruvian Amazon with

87 no connection to either internet or telephone. This study was carried out concurrent to

88 the first survey of the second phase of the NIH-funded International Center of

89 Excellence for Malaria Research (ICEMR) Amazonia project in July 2018. The study

90 area encompasses 6 villages in 2 watersheds, the Mazan River (villages of

91 Gamitanacocha, Libertad and Primero de Enero), and Napo River (villages of Salvador,

92 Lago Yurac Yacu and Urco Miraño) (Fig 1a). This rural setting encompasses primary

93 and secondary forest located north of Iquitos City (capital of Loreto) reachable only by

94 boat transportation ( 2-7 hours from lquitos City). Major landmarks in this area are the

95 river patterns and meanders, strongly influenced by rainfall seasonality. Previous

96 studies have described contrasting malaria epidemiology in both watersheds with

97 complex dynamics related to occupational-related mobility (Parker et al., 2013;

98 Carrasco-Escobar et al., 2017).

99 The first survey of the ICEMR project collected census data, travel records and blood

100 samples (biological data collected were not used for this study). A purposive sampling,

101 proportional to the population size in each community, was carried out based on

102 whether the participant self-reported a trip in the previous month (based on the ICEMR

103 data) and aged 18 years or above. Selected participants were asked to geo-locate the

104 route (a.k.a trajectory) of their recent trip (within a month), either in transit or upon

105 return. All geo-located trajectories were collected in July 2018. 


\section{2.3. ODK and GeoODK setup}

107 Data collection during the first survey of the ICEMR project was implemented in Open

108 Data Kit (ODK - www.opendatakit.org) (Hartung et al., 2010). Briefly, ODK is a flexible

109 open-source suite to collect, store, and manage data in resource-constrained

110 environments. For its part, Geographical Open Data Kit (GeoODK - www.geoodk.com)

111 (University of Maryland and International Institute for Applied Systems Analysis, College

112 Park, USA) expands ODK capabilities with a comprehensive set of GIS-related tools.

113 Both are capable of collecting data online and offline. However, GeoODK requires an

114 MBTile-format base map to collect georeferenced features during offline survey.

115 Both applications were set up using the same Google App Engine server, but

116 applications ran separately on the mobile devices. In this study, Samsung Galaxy Tab

117 A, with 8GB internal memory, Android 5.1, and 7-inch screen tablets were used to better

118 display the base map to participants. A subset of the ICEMR data regarding household

119 geo-reference, socio-demographics and travel records was used in this study. GeoODK

120 and ODK data were linked using common participants' identifiers (PID) in both

121 applications. In addition, a polyline widget was included in GeoODK to show a blank

122 map where participants drew (in fact, georeferenced) the trail of their last movement

123 outside the village. After a brief introduction to the software and a demonstration of the

124 functions (i.e. zoom, and current location), the participants received the tablet and

125 started the polyline creation process. In case the participants required, the interviewer

126 assisted the polyline creation process based on the participant's directions. 
127 A simpler workflow to generate the base map was used in comparison to previous

128 studies (Fornace et al., 2018). A georeferenced tiff image was constructed based on

129 public geographical data from OpenStreetMap (www.openstreetmap.org) and converted

130 to MBtile using maptiler Desktop v. 9.1-1 (Klokan Technologies GmbH -

131 www.maptiler.com). Main landmarks (i.e. river patterns) were validated using available

132 Landsat 8 imagery in the period June-July 2018 (time frame were the travels were

133 taking place). Main villages and river names were added to the base map using QGIS

1342.18 (QGIS Development Team, 2018. QGIS Geographic Information System. Open

135 Source Geospatial Foundation Project. www.qgis.org) for a better orientation of the

136 participants. GeoODK stored a performance log to analyze the start and end time of the

137 complete questionnaire, but also per question.

\section{2.4. Spatial Processing and Statistical Analyses}

139 The KML output of the polyline widget in GeoODK was imported to QGIS. Each

140 geometry corresponds to a participant, and PID were stored by default as an attribute.

141 After initial validation of PID and whether all geometries were inside the study area, a

142 shapefile was generated to improve spatial handling. No additional geo-processing was

143 conducted over raw polylines data. Each polyline was transformed into a layer of points

144 with the QChainage plugin 2.0.1 (Werner Macho, 2017) separated by $1 \mathrm{~m}$. Finally, a

145 heatmap with a radius of $1 \mathrm{~m}$ was constructed using the point layers. GeoODK

146 trajectories and travel record data (destinations) in the ICEMR survey were validated

147 with the National register villages (NRV), that contain GPS coordinates for each official

148 village. Fisher's exact test was used for significance testing of categorical factors

149 between participants included in the ICEMR survey and this study. Spearman's 
150 correlation was used to identify the relationship between the time to complete a

151 GeoODK survey and the trajectory distance recorded per participant. Maps were

152 generated with QGIS. All descriptive analyses and visualizations were produced using

153 R v.3.4.3 (R Development Core Team, R Foundation for Statistical Computing,

154 Australia).

\section{RESULTS}

157 The study population comprised 33 adult subjects between 19-68 yrs of age (mean=41

$158 \mathrm{yrs}$ ), who had lived in the study site for 6 months to $68 \mathrm{yrs}$ (mean=26 yrs). There was no

159 refusal to participate in the study. Most participants were male (67\%); $12 \%$ were

160 illiterate. The most common occupation was farming $60 \% ; 21 \%$ also had fished or

161 hunted during the previous month. Inhabitants reported 1-10 trips per month (mean=2

162 trips/month). Most trips were recreational - e.g., visit to family or friends (36\%), for

163 commerce (21\%), or logging/hunting/fishing (21\%). Several visits were reported to

164 Mazan (48\%) and Iquitos (18\%). The time from origin to destination (hereafter known as

165 transit time) ranged from $1-8 \mathrm{hrs}$ (mean=3 hrs), but $12 \%$ of the population spent more

166 than one day in transit, most commonly for logging or hunting. Overall, the total travel

167 time (transit, stay, return) of $45 \%$ of the population lasted more than 1 day (mean=6

168 days). Of the population who traveled, $73 \%$ slept in a house, whereas $27 \%$ in the forest

169 or in the boat. The average time between the returning date and the GeoODK data

170 collection was 6.8 days (range: $0-25$ days). Importantly, there were no statistically

171 significant differences in age categories ( $p$-value $=0.347$ ), occupation ( $p$-value $=0.305$ ), 
172 and travel reasons ( $p$-value $=0.216$ ) between participants in the ICEMR survey with a

173 travel record and aged 18 years or above $(n=233)$ and this study $(n=33)$.

174 Using GeoODK, all geometries (polylines) were correctly mapped to plausible

175 displacement paths (Fig 1b) along the watercourse, however, in-forest displacements

176 were not possible to validate. All origin and $27(81.8 \%)$ of destination locations were

177 correctly georeferenced, and validated using ICEMR travel records data and NRV data.

178 Six (18.2\%) destinations were not available in NRV, most of them logging or hunting

179 areas. Additional information was obtained with GeoODK, such as different routes to

180 Iquitos city (capital of Loreto Region), and locale of non-documented logging areas

181 where inhabitants work frequently. Overall, recorded trajectories ranged from 10-167 km

182 (mean=42 km), with most of the population $(67 \%)$ displaced less than $50 \mathrm{~km}$. The transit

183 heatmap based on self-reported trajectories depicts more movements along the Mazan

184 River than the Napo River (Fig 1c). The total travel time along the Mazan River ranged

185 from 2 hrs to 14 days (mean=4 days), whereas a lower duration was observed along the

186 Napo River (1 $\mathrm{hr}$ to 19 days (mean=2 days). The average distances of the trajectories of

187 Mazan and Napo River inhabitants were comparable, $48 \mathrm{~km}$ and $35 \mathrm{~km}$ respectively.

188 High variability was observed in Napo River due to some long trajectories to lquitos, and

189 also to occupational-related activities in distant areas of the Mazan River. Overall, the

190 average time to complete the geo-referenced data collection in GeoODK was 8 minutes

191 (range: 1-25 min) per participant, and showed moderate correlation with the distance of

192 the recorded trajectory (Spearman's rho=0.565; $p$-value $=0.002$ ).

193 Marked mobility patterns were observed in this study (Fig 2a). The most common

194 patterns were short displacements $(7.4-22.1 \mathrm{~km})$ in a short period of time $(0-0.3$ 
195 days) $(27 \%)$ and mobility within intermediate distances $(22.2-66.6 \mathrm{~km})$ and intervals

196 (0.4 - 2.6 days) (27\%). Importantly, the greatest distances and periods were related

197 exclusively to logging and hunting activities (Fig 2b). Contrasting distributions of travel

198 time and distance were observed among villages (Fig 2c); however, proximal

199 distributions were observed between villages in the same watersheds (Mazan and

200 Napo). Albeit less marked, a distance/time ratio decay was observed for inhabitants with

201 higher income (Fig 2d).

202

203 4. DISCUSSION

204 In settings with scattered foci of infection, connectivity is a cornerstone for the

205 maintenance of malaria transmission. Although the use of big data and actively data-

206 collecting wearables pave the way for a comprehensive understanding of the role of

207 human mobility in infectious diseases dynamics, these technologies are not available in

208 many of the rural populations that comprise most malaria transmission settings. This

209 study demonstrated the feasibility and the added value of a novel open mobile mapping

210 tool to assess human mobility in rural offline populations. Importantly, this approach

211 allowed for mobility profiling in communities with contrasting malaria transmission and

212 determined, to our knowledge, the first characterization of human mobility patterns in

213 the rural riverine Peruvian Amazon.

214 The study case setting, Mazan, is classified as a high malaria transmission intensity

215 district by the Ministry of Health $(\mathrm{MoH})$ with an intricate river network where most

216 villages are located. The findings of this study set the stage for the accurate detection 
217 and analysis of human mobility patterns in rural riverine settings. The use of GeoODK

218 permitted the collection of detailed trajectories that would have been lost using

219 traditional collection methods. Highlighted benefits include documentation of different

220 routes to the same destination, and precise geo-localization of occupational-related

221 areas. Regarding the former, two main routes to lquitos city were observed. Trajectories

222 passed through Mazan or Indiana, both commerce-dedicated cities with well-equipped

223 health centers, yet with different malaria incidence rates. Regarding geo-localization of

224 occupational-related areas, there are illegal logging and hunting areas, and no official

225 human settlements that lack georeferenced data (NRV data). Thus this approach

226 complemented the self-reported surveyed data to better understand travel distances

227 and disease exposure of these riverine populations (Parker et al., 2013), that otherwise

228 would not be possible since there is not official GPS registers of these locations.

229 A recent study demonstrated the accuracy of GeoODK for household mapping,

230 reflecting the spatial orientation of inhabitants when exposed to a blank map (Fornace

231 et al., 2018). Consistently, all reported origins and destinations in the ICEMR survey

232 with available geo-referenced data (NRV data) were correctly mapped with GeoODK.

233 Participants were able to distinguish and georeference their trajectory through different

234 areas within cities or villages that commonly would be lost using structured forms. This

235 is a relevant feature given the fact that there are no addresses in most rural and riverine

236 communities that could be georeferenced, and highly heterogeneous malaria

237 transmission within riverine communities has been reported previously (Carrasco-

238 Escobar et al., 2017). 
239 Although this is a proof-of-concept study, we found interesting aspects of malaria

240 dynamics in this area. From both watersheds, a more intensive travel transit was

241 observed in the Mazan River. Consistently, higher risk of malaria infection (Chuquiyauri

242 et al., 2013; Carrasco-Escobar et al., 2017) and vector exposure (Parker et al., 2013)

243 have been reported in communities along the Mazan River. Population genetic studies

244 in the area detected high heterozygosity and polyclonal infections that were

245 hypothesized to be due to high human mobility (Van den Eede et al., 2010). This

246 intensified malaria dynamic presumably arose from continuous commerce, logging and

247 hunting-related mobility, a factor that was reported as key for greater risk of

248 Plasmodium vivax malaria across Peruvian, Colombian, and the Brazilian Amazon

249 (Sevilla-Casas, 1993; da Silva-Nunes et al., 2008; Hahn et al., 2014; Carrasco-Escobar

250 et al., 2017) and other malaria settings (Smith et al., 2017). Moreover, the fact that all

251 logging and hunting areas reported by participants were mapped only along the Mazan

252 River, and the distribution of travel time and distances were highly heterogeneous

253 between watersheds (Salonen et al., 2012), supports the idea that malaria control might

254 be addressed at a larger scale, among high-connectivity units.

255 The data reported here were obtained at a meso-scale (study area extent $=50 \mathrm{~km}^{2}$ ), but

256 depending on the research question and the base map used in GeoODK, this approach

257 could be conducted at a micro- or macro-scale in a variety of fields. The increased

258 evidence of exophagic biting behavior of $\mathrm{Ny}$. darlingi in the Peruvian Amazon (Reinbold-

259 Wasson et al., 2012; Moreno et al., 2015), urges better understanding of outdoor

260 activities and human mobility patterns to tailor malaria control strategies. In addition,

261 spatial and molecular epidemiology (Delgado-Ratto et al., 2016), among other 
262 disciplines, would benefit from accurate human mobility estimates in resource-limited

263 settings. However, longitudinal studies on human mobility are highly recommended.

264 Temporal and seasonal trends of human mobility might better elucidate the underlying

265 malaria exposure (Wesolowski et al., 2012; Tatem et al., 2014; Ruktanonchai et al.,

266 2016; Smith et al., 2017; Wesolowski et al., 2017).

267 While, encouragingly, the performance of GeoODK to collect human mobility data

268 appear to be reliable regardless of phone network structure or environmental conditions,

269 we find that several validity assessments must be conducted to scale-up its

270 implementation. Firstly, despite a large amount of destinations were possible to validate

271 using travel surveys or National datasets, still remaining the validation of movement

272 data during transit or return. This would be possible outside of forested riverine systems

273 where GPS tracker data, or mobile or GLH data could be used to validate the self-

274 reported trajectories in GeoODK. The use of GPS trackers with survey-grade receivers

275 is suggested as a validation method for travel time and in-forest displacements, since

276 dual-frequency acquisition outperformed other GPS receivers in forested areas.

277 Regrettably, the cost of survey-grade GPS receivers deters its use in population-based 278 epidemiological studies.

\section{5. CONCLUSSION}

281 In conclusion, a feasible approach to map human mobility traceability in rural villages

282 was presented in this study. Although our findings allowed for the construction of a

283 human mobility framework in the Peruvian Amazon, additional work must be conducted 
284 to deepen our understanding of human mobility that could facilitate tailor-made malaria

285 control activities, and mark a turning point for watershed- or mobility-circuit- based

286 control approaches.

288 Data accessibility. Shapefiles and metadata are available at figshare

289 (10.6084/m9.figshare.7091075 and 10.6084/m9.figshare.7091078)

290

291

292

293

294

295

296

297

298

299

300

301

302

303

304

Acknowledgements. We thank Prof. Jan Evelyn Conn and Prof. Kimberly Brouwer for editing and proof-reading the manuscript; Dr. Hugo Rodriguez Ferrucci and Edgar Manrique for their valuable discussions and suggestions.

\section{REFERENCES}

Barabási A-L. 2009. Scale-Free Networks: A Decade and Beyond. Science 325:412413. DOI: $10.1126 /$ science.1173299.

Buckee CO, Tatem AJ, Metcalf CJE. 2017. Seasonal Population Movements and the Surveillance and Control of Infectious Diseases. Trends in Parasitology 33:1020. DOI: 10.1016/j.pt.2016.10.006.

Buckee CO, Wesolowski A, Eagle NN, Hansen E, Snow RW. 2013. Mobile phones and malaria: Modeling human and parasite travel. Travel Medicine and Infectious Disease 11:15-22. DOI: 10.1016/j.tmaid.2012.12.003.

Carrasco-Escobar G, Gamboa D, Castro MC, Bangdiwala SI, Rodriguez H, ContrerasMancilla J, Alava F, Speybroeck N, Lescano AG, Vinetz JM, Rosas-Aguirre A, 
Llanos-Cuentas A. 2017. Micro-epidemiology and spatial heterogeneity of P . vivax parasitaemia in riverine communities of the Peruvian Amazon: A multilevel analysis. Scientific Reports 7:8082. DOI: 10.1038/s41598-017-07818-0.

Chuquiyauri R, Peñataro P, Brouwer KC, Fasabi M, Calderon M, Torres S, Gilman RH, Kosek M, Vinetz JM. 2013. Microgeographical differences of Plasmodium vivax relapse and re-infection in the Peruvian Amazon. The American Journal of Tropical Medicine and Hygiene 89:326-338. DOI: 10.4269/ajtmh.13-0060.

312 Danskin SD, Bettinger P, Jordan TR, Cieszewski C. 2009. A Comparison of GPS

313 Performance in a Southern Hardwood Forest: Exploring Low-Cost Solutions for

314 Forestry Applications. Southern Journal of Applied Forestry 33:9-16. DOI: 10.1093/sjaf/33.1.9.

316 Delgado-Ratto C, Gamboa D, Soto-Calle VE, Eede PV den, Torres E, SánchezMartínez L, Contreras-Mancilla J, Rosanas-Urgell A, Ferrucci HR, Llanos-

321 Findlater A, Bogoch II. 2018. Human Mobility and the Global Spread of Infectious Cuentas A, Erhart A, Geertruyden J-PV, D’Alessandro U. 2016. Population Genetics of Plasmodium vivax in the Peruvian Amazon. PLOS Negl Trop Dis 10:e0004376. DOI: 10.1371/journal.pntd.0004376.

Diseases: A Focus on Air Travel. Trends in Parasitology 34:772-783. DOI: 10.1016/j.pt.2018.07.004.

Fornace KM, Surendra H, Abidin TR, Reyes R, Macalinao MLM, Stresman G, Luchavez J, Ahmad RA, Supargiyono S, Espino F, Drakeley CJ, Cook J. 2018. Use of mobile technology-based participatory mapping approaches to geolocate health 
facility attendees for disease surveillance in low resource settings. International Journal of Health Geographics 17. DOI: 10.1186/s12942-018-0141-0.

329 Funk S, Salathé M, Jansen VAA. 2010. Modelling the influence of human behaviour on

330 the spread of infectious diseases: a review. Journal of The Royal Society Interface:rsif20100142. DOI: 10.1098/rsif.2010.0142.

332 González MC, Hidalgo CA, Barabási A-L. 2008. Understanding individual human mobility patterns. Nature 453:779-782. DOI: 10.1038/nature06958.

334 Hahn MB, Gangnon RE, Barcellos C, Asner GP, Patz JA. 2014. Influence of

335

336

337 Deforestation, Logging, and Fire on Malaria in the Brazilian Amazon. PLOS ONE 9:e85725. DOI: 10.1371/journal.pone.0085725.

Hartung C, Lerer A, Anokwa Y, Tseng C, Brunette W, Borriello G. 2010. Open data kit: tools to build information services for developing regions. In: Proceedings of the 4th ACM/IEEE International Conference on Information and Communication Technologies and Development. ACM, 18.

Martens P, Hall L. 2000. Malaria on the move: human population movement and malaria transmission. Emerging Infectious Diseases 6:103-109.

Moreno M, Saavedra MP, Bickersmith SA, Lainhart W, Tong C, Alava F, Vinetz JM, Conn JE. 2015. Implications for changes in Anopheles darlingi biting behaviour in three communities in the peri-Iquitos region of Amazonian Peru. Malaria Journal 14:290. DOI: 10.1186/s12936-015-0804-2.

Parker BS, Paredes Olortegui M, Peñataro Yori P, Escobedo K, Florin D, Rengifo Pinedo S, Cardenas Greffa R, Capcha Vega L, Rodriguez Ferrucci H, Pan WK, Banda Chavez C, Vinetz JM, Kosek M. 2013. Hyperendemic malaria 
transmission in areas of occupation-related travel in the Peruvian Amazon. Malaria Journal 12:178. DOI: 10.1186/1475-2875-12-178.

352 Peeters Grietens K, Gryseels C, Dierickx S, Bannister-Tyrrell M, Trienekens S, Uk S, Phoeuk P, Suon S, Set S, Gerrets R, Hoibak S, Muela Ribera J, HausmannMuela S, Tho S, Durnez L, Sluydts V, d'Alessandro U, Coosemans M, Erhart A. 2015. Characterizing Types of Human Mobility to Inform Differential and Targeted Malaria Elimination Strategies in Northeast Cambodia. Scientific Reports 5:16837. DOI: 10.1038/srep16837.

Perchoux C, Chaix B, Cummins S, Kestens Y. 2013. Conceptualization and measurement of environmental exposure in epidemiology: accounting for activity space related to daily mobility. Health \& Place 21:86-93. DOI: 10.1016/j.healthplace.2013.01.005.

362 Pindolia DK, Garcia AJ, Wesolowski A, Smith DL, Buckee CO, Noor AM, Snow RW, Tatem AJ. 2012. Human movement data for malaria control and elimination strategic planning. Malaria Journal 11:205. DOI: 10.1186/1475-2875-11-205.

365 Prothero RM. 1977. Disease and mobility: a neglected factor in epidemiology. International Journal of Epidemiology 6:259-267.

367 Reinbold-Wasson DD, Sardelis MR, Jones JW, Watts DM, Fernandez R, Carbajal F, 368 Pecor JE, Calampa C, Klein TA, Turell MJ. 2012. Determinants of Anopheles seasonal distribution patterns across a forest to periurban gradient near lquitos,

370 Peru. The American Journal of Tropical Medicine and Hygiene 86:459-463. DOI: 10.4269/ajtmh.2012.11-0547. 
372 Rempel RS, Rodgers AR, Abraham KF. 1995. Performance of a GPS Animal Location

373 System under Boreal Forest Canopy. The Journal of Wildlife Management 59:543-551. DOI: 10.2307/3802461.

375 Ruktanonchai NW, DeLeenheer P, Tatem AJ, Alegana VA, Caughlin TT, Erbach-

382
Ruktanonchai NW, Ruktanonchai CW, Floyd JR, Tatem AJ. 2018. Using Google Location History data to quantify fine-scale human mobility. International Journal of Health Geographics 17:28. DOI: 10.1186/s12942-018-0150-z. Malaria Transmission Foci for Elimination Using Human Mobility Data. PLOS Computational Biology 12:e1004846. DOI: 10.1371/journal.pcbi.1004846.

Salonen M, Toivonen T, Cohalan J-M, Coomes OT. 2012. Critical distances: Comparing measures of spatial accessibility in the riverine landscapes of Peruvian Amazonia. Applied Geography 32:501-513. DOI: 10.1016/j.apgeog.2011.06.017. Searle KM, Lubinda J, Hamapumbu H, Shields TM, Curriero FC, Smith DL, Thuma PE, Moss WJ. 2017. Characterizing and quantifying human movement patterns using GPS data loggers in an area approaching malaria elimination in rural southern Zambia. Royal Society Open Science 4:170046. DOI: 10.1098/rsos.170046.

Sevilla-Casas E. 1993. Human mobility and malaria risk in the Naya river basin of Colombia. Social Science \& Medicine (1982) 37:1155-1167.

Sigrist P, Coppin P, Hermy M. 1999. Impact of forest canopy on quality and accuracy of GPS measurements. International Journal of Remote Sensing 20:3595-3610. DOI: 10.1080/014311699211228. 
394 da Silva-Nunes M, Codeço CT, Malafronte RS, da Silva NS, Juncansen C, Muniz PT,

395 Ferreira MU. 2008. Malaria on the Amazonian frontier: transmission dynamics,

396 risk factors, spatial distribution, and prospects for control. The American Journal

397 of Tropical Medicine and Hygiene 79:624-635.

398 Smith JL, Auala J, Haindongo E, Uusiku P, Gosling R, Kleinschmidt I, Mumbengegwi D,

399 Sturrock HJW. 2017. Malaria risk in young male travellers but local transmission

400 persists: a case-control study in low transmission Namibia. Malaria Journal

401 16:70. DOI: 10.1186/s12936-017-1719-x.

402 Stoddard ST, Morrison AC, Vazquez-Prokopec GM, Paz Soldan V, Kochel TJ, Kitron U, 403

404

405 Elder JP, Scott TW. 2009. The role of human movement in the transmission of vector-borne pathogens. PLoS neglected tropical diseases 3:e481. DOI: 10.1371/journal.pntd.0000481.

Sturrock HJW, Roberts KW, Wegbreit J, Ohrt C, Gosling RD. 2015. Tackling Imported Malaria: An Elimination Endgame. The American Journal of Tropical Medicine and Hygiene 93:139-144. DOI: 10.4269/ajtmh.14-0256.

Tatem AJ, Huang Z, Narib C, Kumar U, Kandula D, Pindolia DK, Smith DL, Cohen JM, Graupe B, Uusiku P, Lourenço C. 2014. Integrating rapid risk mapping and mobile phone call record data for strategic malaria elimination planning. Malaria

413 Tatem AJ, Smith DL. 2010. International population movements and regional

414 Plasmodium falciparum malaria elimination strategies. Proceedings of the National Academy of Sciences 107:12222-12227. DOI:

416

$$
\text { 10.1073/pnas.1002971107. }
$$


417 Van den Eede P, Van der Auwera G, Delgado C, Huyse T, Soto-Calle VE, Gamboa D,

418 Grande T, Rodriguez H, Llanos A, Anné J, Erhart A, D’Alessandro U. 2010.

419 Multilocus genotyping reveals high heterogeneity and strong local population structure of the Plasmodium vivax population in the Peruvian Amazon. Malaria Journal 9:151. DOI: 10.1186/1475-2875-9-151.

422

Vazquez-Prokopec GM, Bisanzio D, Stoddard ST, Paz-Soldan V, Morrison AC, Elder JP, Ramirez-Paredes J, Halsey ES, Kochel TJ, Scott TW, Kitron U. 2013. Using GPS Technology to Quantify Human Mobility, Dynamic Contacts and Infectious Disease Dynamics in a Resource-Poor Urban Environment. PLOS ONE 8:e58802. DOI: 10.1371/journal.pone.0058802.

Wesolowski A, Buckee CO, Engø-Monsen K, Metcalf CJE. 2016. Connecting Mobility to Infectious Diseases: The Promise and Limits of Mobile Phone Data. The Journal of Infectious Diseases 214:S414-S420. DOI: 10.1093/infdis/jiw273.

Wesolowski A, Eagle N, Tatem AJ, Smith DL, Noor AM, Snow RW, Buckee CO. 2012. Quantifying the Impact of Human Mobility on Malaria. Science 338:267-270. DOI: $10.1126 /$ science.1223467.

Wesolowski A, Erbach-Schoenberg E zu, Tatem AJ, Lourenço C, Viboud C, Charu V, Eagle N, Engø-Monsen K, Qureshi T, Buckee CO, Metcalf CJE. 2017. Multinational patterns of seasonal asymmetry in human movement influence infectious disease dynamics. Nature Communications 8:2069. DOI: 10.1038/s41467-017-02064-4.

\section{FIGURE LEGENDS}


440 Figure 1. Study area in Mazan district, Loreto Region, Peruvian Amazon. a) Locale

441 of Gamitanacocha (GC), Libertad (LI), Primero de Enero (PE), Salvador (SL), Lago

442 Yurac Yacu (YY) and Urco Miraño (UM). b) Polylines (or trajectories) collected with

443 GeoODK, each color represents a participant. c) Heatmap of transit based on

444 trajectories. Maps were produced using QGIS, and the base maps was obtained from

445 OpenStreetMap (www.openstreetmap.org) and OpenTopoMap

446 (www.opentopomap.org), under CC BY-SA 3.0.

447 Figure 2. Mobility patterns of inhabitants of Mazan district. a) Distribution of profiles

448 among categories of trip distance and time (X-and $\mathrm{Y}$ - axes in logarithmic scale). b)

449 Travel patterns per trip reason. c) Distribution of travel time and distance between

450 villages (villages abbreviations on Y-axis as in Fig 1). d) Stratified distribution of the ratio

451 distance/time according to income. 
Figure 1

Study area in Mazan district, Loreto Region, Peruvian Amazon.

a) Locale of Gamitanacocha (GC), Libertad (LI), Primero de Enero (PE), Salvador (SL), Lago Yurac Yacu (YY) and Urco Miraño (UM). b) Polylines (or trajectories) collected with GeoODK, each color represents a participant. c) Heatmap of transit based on trajectories. Maps were produced using QGIS, and the base maps was obtained from OpenStreetMap ( www.openstreetmap.org ) and OpenTopoMap ( www.opentopomap.org ), under CC BY-SA 3.0.

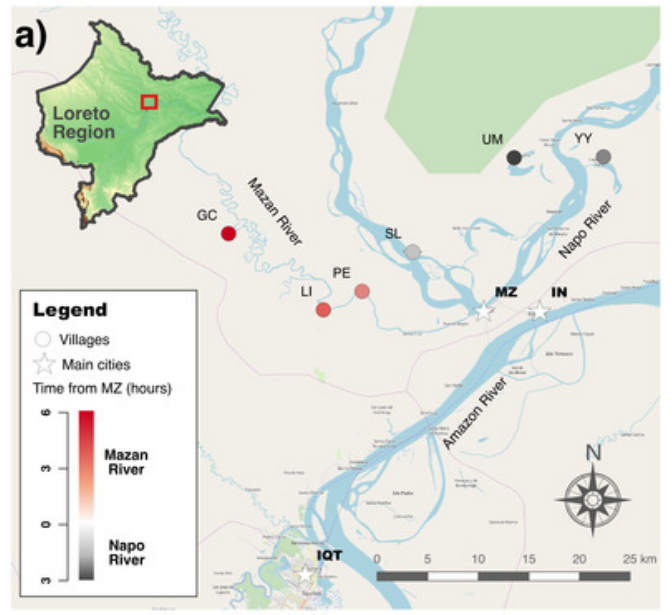

b)

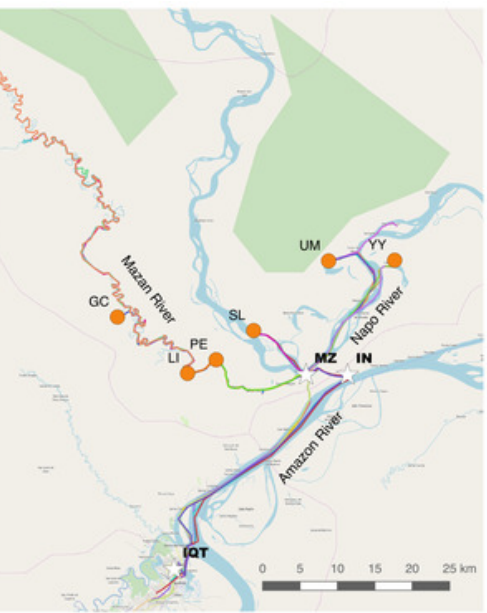

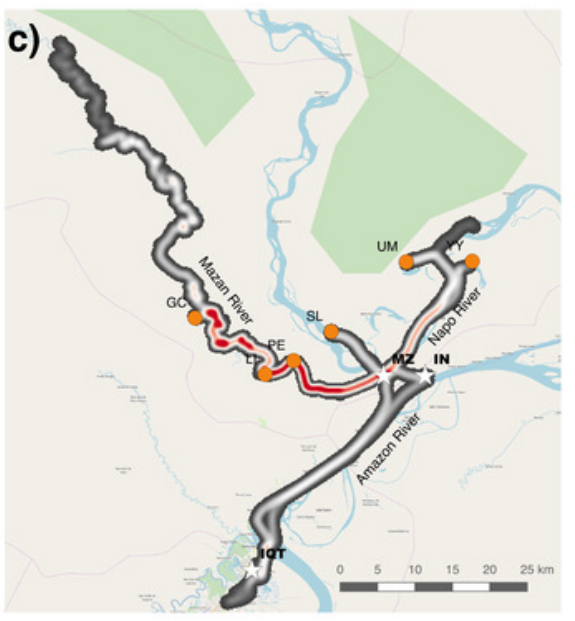


Figure 2

Mobility patterns of inhabitants of Mazan district.

a) Distribution of profiles among categories of trip distance and time ( $X$ - and $Y$ - axes in logarithmic scale). b) Travel patterns per trip reason. c) Distribution of travel time and distance between villages (villages abbreviations on Y-axis as in Fig 1). d) Stratified distribution of the ratio distance/time according to income.

a)

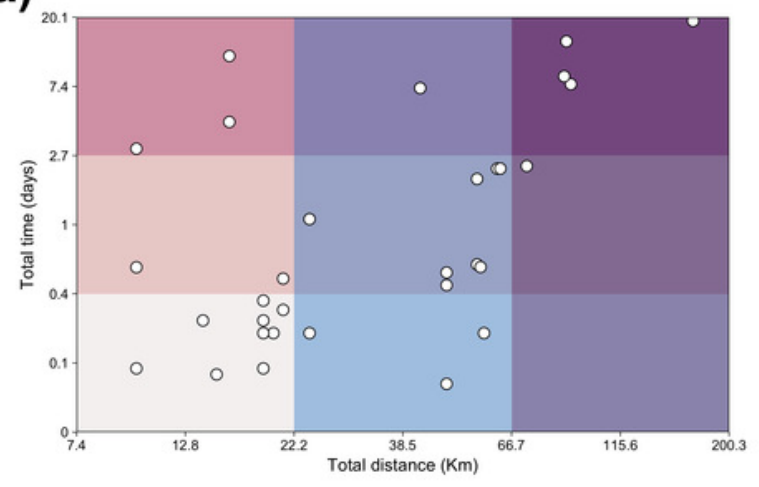

c)

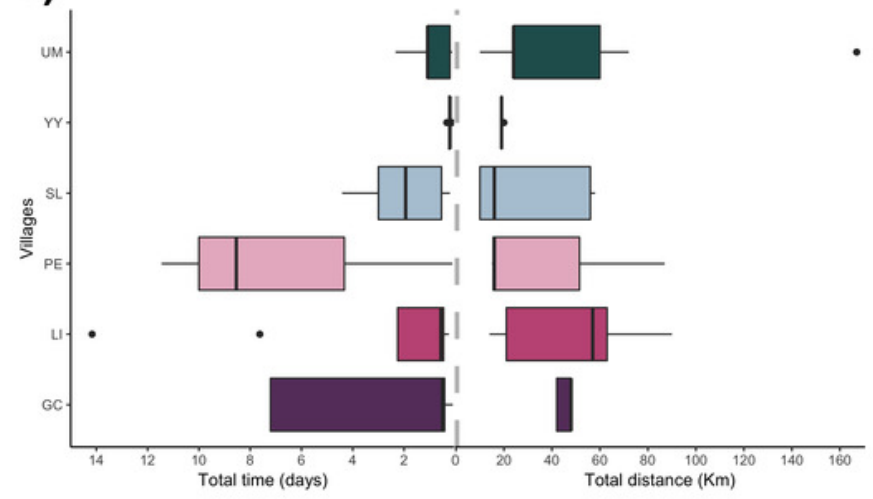

b)

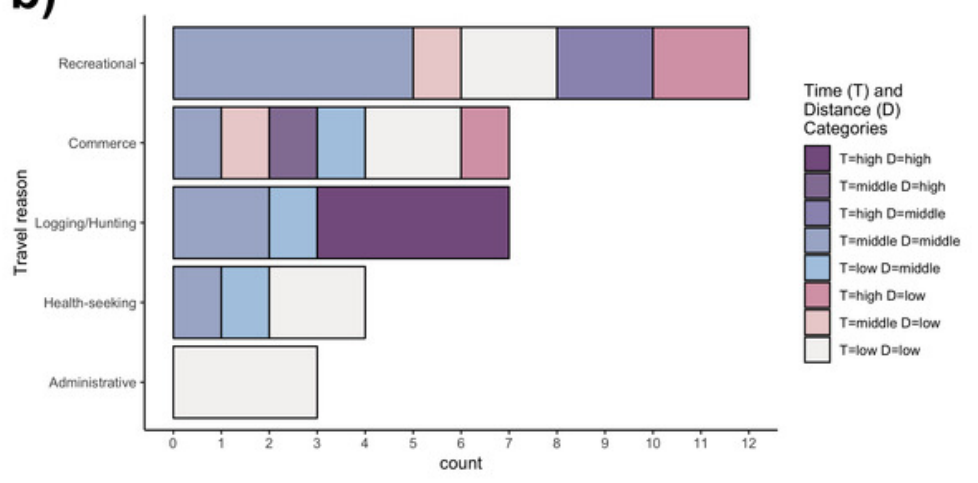

d)

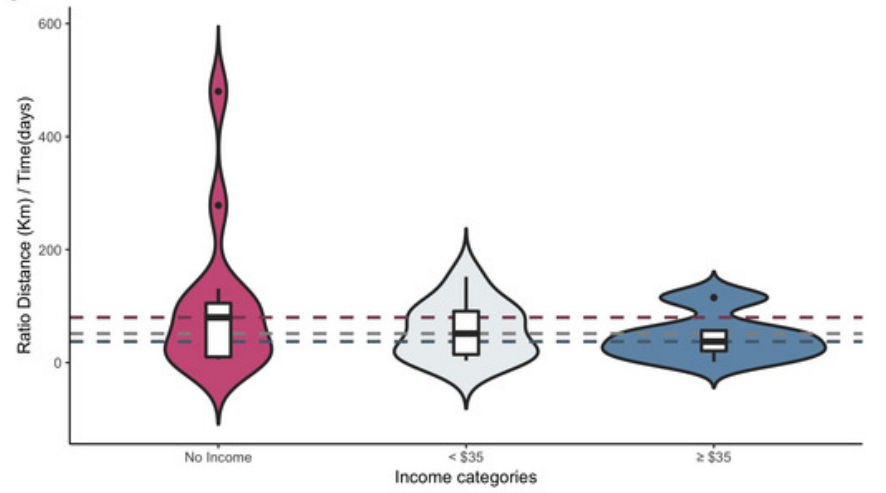

